\title{
Thermal Changes in the Magnetic Properties of an Anomalously Magnetic Mineral
}

\author{
Vladimír Kropáček \\ Geophysical Institute, Czechosl. Acad. Sci., Prague, Czechoslovakia
}

(Received August 17, 1967)

\begin{abstract}
The paper decribes influences of thermal treatment of a complex natural mineral from the Magnet Cove on its magnetic properties. This mineral is characterized by an anomalously high magnetization. Its thermal dependence, specific remanent magnetization and its stability were studied in detail on this mineral. These studies resulted in the definition of some characteristics of the NRM.
\end{abstract}

\section{Introduction}

The aim of this paper is to elucidate the effect of thermal treatment on changes of magnetic properties of a strongly magnetic mineral, which is stored in the National Museum in Prague under No. 21995, and which comes from the Magnet Cove locality in Arkansas. This mineral was part of the collection treated by M. Krs and J. Hak, who carried out X-ray and chemical analyses. So far the mineral has not been identified unambiguously. It is a complex natural ferrite which a spinel lattice containing a considerable amount of Tiand $\mathrm{Mg}$. The magnetic properties of this mineral are anomalous in some cases, its specific saturation magnetization $\sigma_{s s}=104,2 \mathrm{emu} / \mathrm{gr}$. is higher than any as yet known natural ferrimagnetic mineral. When the mineral is heated considerable changes are experienced, and the mineral turns to a solid solution of titanomagnetites with different contents of $\mathrm{Ti}$ and $\mathrm{Mg}$. This results in pronounced changes of the magnetic properties, thus rendering the mineral highly suitable for the determination of the effect of thermal treatment on the changes of magnetic properties.

\section{Instruments and Methodology of Measurements}

A magnetic balance of the MW-1 type (Frölich, 1959) was used for measuring the temperature dependence of the specific saturation magnetization $\sigma_{s}(T)$ and for the determination of Curie temperature. The accuracy in derermining the latter was $\pm 1,5^{\circ} \mathrm{C}$. The samples to be measured were in powder form. They were placed in a silver hermetically closed container excluding the access of air, the weight of the sample being roughly $0,005 \mathrm{gr}$. The callibration of the magnetic balance was done experimentally from the known values of the specific saturation magnetization for pure $\mathrm{Ni}$ and $\mathrm{Fe}$. The sensitivity of the balance was determined basing on ten measured values for $\mathrm{Ni}$ and $\mathrm{Fe}$, while the impurities did not exceed $0,01 \%$.

The samples used for measurements of specific remanent magnetization had the shape 
of a rotational ellipsoid with the semi-major axis $a=1 \mathrm{~mm}$ and the semi-minor axes $b=c=$ $0,5 \mathrm{~mm}$. The weight of the samples was about $0,03 \mathrm{gr}$. and the density of the samples $\rho=$ $4,2 \mathrm{gr}$. per $\mathrm{cm}^{3}$. Measurements of the remanent magnetization were carried out on an astatic Dolginov's magnetometer of the Geophysical Institute of the Academy of Sciences in Prague, with a sensitivity of $\varepsilon \approx 5.10^{-5}$ Oe per scale division, and on an astatic magnetometer of the Institute of Applied Geophysics in Prague, which has a sensitivity $\varepsilon=2.10^{-7}$ Oe per scale division. The A.C. demagnetization was carried out on an instrument belonging to the Institute of Applied Geophysics in Prague. This instrument had a ratio of rotation around two mutually perpendicular axes of $4: 5$ in a compensated Earth's magnetic field. A permanent magnetic field was created by a small electromagnet with a maximum field intensity of $10,000 \mathrm{Oe}$ and space of $0,75 \mathrm{~cm}$ between pole extensions. The samples were heated in a non-magnetic ceramic furnace in a compensated magnetic field. In order to prevent the samples from oxidizing they were placed in the middle of a ceramic cube with $0,6 \mathrm{~cm}$ sides.

In order to determine the Curie temperature $\theta$, a parabolic extrapolation of the temperature curve $\sigma_{s}(T)$ was used in the immediate vicinity of the Curie temperature, from temperatures under which paraprocesses do not yet appear up to the value of $\sigma_{s}(T)=0$. The use of the parabolic extrapolation follows from the theoretical thermodynamic dependence of ferromagnetic materials in the immediate vicinity of the Curie temperature (Kneller, 1962):

$$
\left[\sigma_{s}(T) / \sigma_{s o}\right]^{2}=\text { const }(\theta-T)=f(T) .
$$

The function $f(T)$ is in a linear dependence on the temperature, and if we express it graphically, the Curie temperature can be determined with quite good accuracy, i.e. $\pm 2{ }^{\circ} \mathrm{C}$. Because of the influence of inhomogeneities of the material the linearity of the function $f(T)$ will not hold in all cases, and the determination of the Curie temperature in these cases will be considerably less accurate. These cases will be demonstrated by the nonlinearity of the function $f(T)$. Control measurements of Curie temperatures were carried by DTA (Stiller and Vollstädt 1965), and with the help of the temperature dependent specific remanent magnetization.

\section{The Properties of Specific Saturation Magnetization of the Mineral Investigated}

The basic curve of the temperature dependence of the specific saturation magnetization $\sigma_{s}(T)$ of the given mineral in its natural state is shown in Fig. 1, by curve 1: cf. K. Kobayashi (1959) and T. Nagata (1961). Unless otherwise stated, all the heating and cooling processes were carried out at the speed of $200^{\circ} \mathrm{C}$ per hour. Curve 2 corresponds to the cooling process initiated at $600^{\circ} \mathrm{C}$. In the thermally treated sample, the temperature dependence curve $\sigma_{s}(T)$ is reversible, unless $600^{\circ} \mathrm{C}$ are exceeded. In order to verify this fact, control measurements of $\left.\sigma_{s}(t)\right|_{T=\text { const. }}$ where $t$ is time and $T$ the chosen temperature, were carried out, with the sample being kept at temperature $T$ over the given interval. Samples were kept heated as long as 24 hours at temperatures of $400^{\circ}, 450^{\circ}, 500^{\circ}$ and $600^{\circ} \mathrm{C}$. Decreases of the respective values of $\sigma_{s}(T)$ were not observed.

As was found by X-ray analysis, the mineral undergoes certain changes when heated 
and it changes to titanomagnetites. The chemical formula of the titanomagnetite series is written in the form $(1-x) . \mathrm{Fe}_{3} \mathrm{O}_{4} \cdot x \mathrm{TiFe}_{2} \mathrm{O}_{4}$ and this series is characterized by the changes in the value of saturation magnetization and the Curie temperature dependent on $x$ (Akimoto et al., 1957).

To make clear at which temperatures the changes of magnetic properties take place, a modified thermomagnetic analysis was carried out, because the initial mineral and the heated mineral showed different values of specific saturation magnetization and Curie temperatures. Steps of $50^{\circ} \mathrm{C}$ were chosen as suitable for the modified thermomagnetic analysis, with a special value taken at $475^{\circ} \mathrm{C}$. The mineral sample was heated to temperatures gradually rising step by step, and cooled again to room temperature. The result of this thermomagnetic analysis is shown in graphic form in Fig. 2. It is clear that up to about $350^{\circ} \mathrm{C}$ the curve $\sigma_{s}(T) / \sigma_{s o}$ is fully reversible. /The changes in the value of the initial saturation magnetization are within the limits of observational errors; $\sigma_{s o}$ is the value of specific saturation magnetization at $0^{\circ} \mathrm{C} /$ This is designated by curve 1 . When the sample is heated up to $400^{\circ} \mathrm{C}$, the trend of the curve is different during cooling in comparison to curve 1 , and the results is shown by curve 2 . In general it can be said that at each temperature step even when

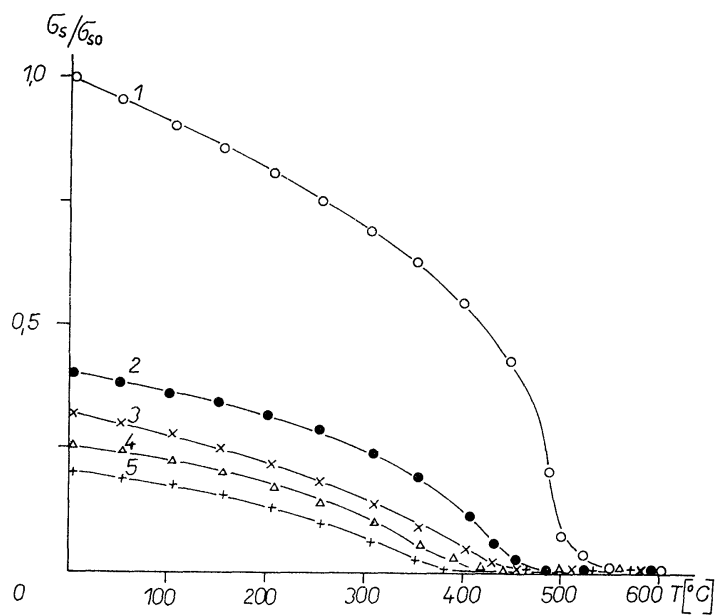

Fig. 1 Temperature dependence of the specific saturation magnetization $\sigma_{s}(T) / \sigma_{s o}$ during various thermal treatments; curve 1 -natural state, curve 2 -after heating up to $600^{\circ} \mathrm{C}$ and cooling by speed $200^{\circ} \mathrm{C}$ per hour, curve 3 -after heating up to $800^{\circ} \mathrm{C}$ and abrupt cooling, curve 4 -after heating up to $800^{\circ} \mathrm{C}$ for 3 hours and cooling by speed for $200^{\circ} \mathrm{C}$ per hour, Curve 5-after heating up to $800^{\circ} \mathrm{C}$ for 24 hours and cooling.

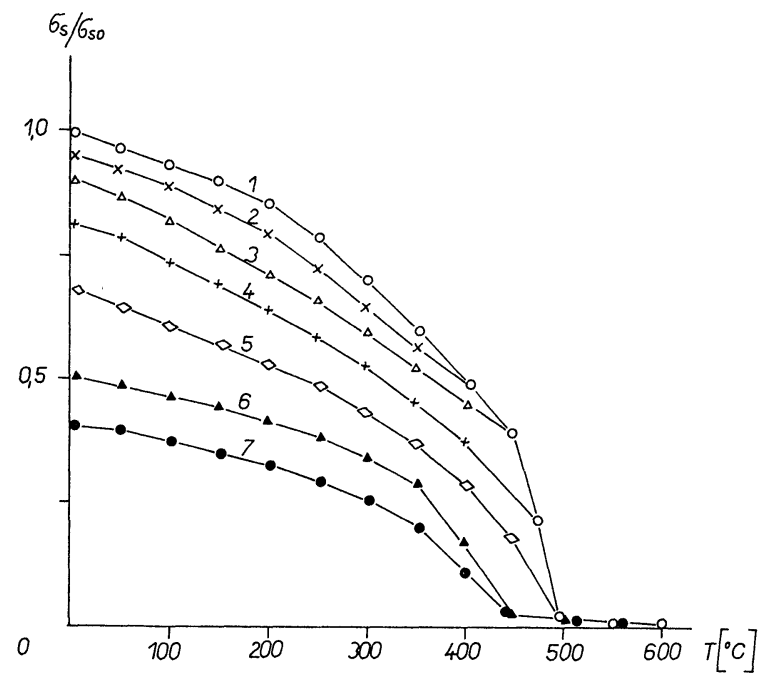

Fig. 2 Thermomagnetic curves for the modified thermomagnetic analysis carried out at steps of $50^{\circ} \mathrm{C}$ with an intermediate step at $475^{\circ} \mathrm{C}$. the sample is heated to temperature $T_{i}>\sim 350^{\circ} \mathrm{C}$, the trend of $\sigma_{s}(T) / \sigma_{s o}$ is along curve $i-1$ up to temperature $T_{i-1},\left(T_{i-1}=T_{i}-\right.$ $50^{\circ} \mathrm{C}$ ); from temperature $T_{i}, \sigma_{s}(T) / \sigma_{s o}$ returns along curve $i(i=1,2, \ldots, 7)$. Finally, the values of $\sigma_{s o}{ }^{(i)}$ decrease gradually from the initial value $\sigma^{(1)}{ }_{s o}=104,2$ emu per gr. to $\sigma^{(7)}{ }_{s o}=42,5 \mathrm{emu}$ 
per gr. after the sample had been heated to $T=600^{\circ} \mathrm{C}$. The decrease in values of $\sigma^{(i)}{ }_{s o}$ as a function of the maximum heating temperature is given in Table 1.

Table 1 Change of magnetic parameters during thermal treatment of the given mineaal

\begin{tabular}{c|c|c|c|c|c|c|c|c|c}
\hline $\begin{array}{c}\text { Maximum } \\
\text { temperature } \\
\text { of heating }\left({ }^{\circ} \mathrm{C}\right)\end{array}$ & $0-350$ & 400 & 450 & 500 & 600 & $\begin{array}{c}|c| \\
\text { abrupt } \\
\text { cooling }\end{array}$ & $3^{\mathrm{h}}$ & $24^{\mathrm{h}}$ & 1200 \\
\hline$\theta^{\circ} \mathrm{C}$ & 494 & 494 & 494 & 494 & 463 & 442 & 434 & 428 & $\sim 375$ \\
\hline $\begin{array}{c}\sigma_{\text {so }} \\
\text { emu per gr. }\end{array}$ & 104,2 & 99,1 & 94,7 & 69,2 & 42,6 & 38,0 & 26,2 & 20,8 & - \\
\hline $\begin{array}{c}\sigma_{\text {rso }} \\
\text { emu per gr. }\end{array}$ & 1,74 & 1,56 & - & 1,41 & 1,36 & 1,22 & 1,26 & 1,19 & 0,92 \\
\hline
\end{tabular}

The change in $\sigma_{s o}$ values is accompaied by changes in Curie temperatures, which in comparison to the changes in the values of specific saturation magnetization, can be experienced only after heating the samples to temperatures higher than $500^{\circ} \mathrm{C}$. This includes curves 6 and 7 , whereas curve 5 , corresponding to heating the sample up to $500^{\circ} \mathrm{C}$, still shows the reversible trend, as far as the change in the Curie temperature is concerned. A significant fact resulting from this thermomagnetic analysis is the agreement of the envelope curve gained from the $\sigma^{(i)}(T) / \sigma_{s}$ values with curve 1 in Fig. 1 . This proves the statements mentioned to be correct. Having completed the thermomagnetic analysis, it is possible to characterize the magnetic changes which take place in the mineral during thermal treatment up to $600^{\circ} \mathrm{C}$ as follows:

1. A decrease in the value of the specific saturation magnetization is experienced. This change takes place apparently very quickly, because control measurements carried out at a heating speed of $1000^{\circ} \mathrm{C}$ per hour gave the same results as measurements carried out at heating speed of $200^{\circ} \mathrm{C}$ per hour. Further changes in the value of the saturation magnetization dependent on the time of heating up to temperatures of $600^{\circ} \mathrm{C}$ were not experienced (providing the 24 hours interval is not exceeded).

2. A decrease in the Curie temperature is experienced in relation to the maximum temperature of heating, but in contrast to the changes in the value of saturation magnetization, which occur at temperatures over $350^{\circ} \mathrm{C}$, the changes in the Curie temperatures take place at temperatures over $500^{\circ} \mathrm{C}$.

As has already been mentioned, not even thermal treatment for a period of 24 hours at $600^{\circ} \mathrm{C}$ changed the value of the specific saturation magnetization in comparison to the value acquired by heating the samples to the same temperature for a much shorter time. Therefore, either this temperature is insufficient for further changes to occour (mixing, exsolution, oxidation, etc.), or more likely, the time for which heating at higher temperatures takes place, is insufficiently long so that the changes could occur later on. These results are partly inconsistent with those of Bewersdorff (1961), who in contrast to the mixing of titanomagnetites occuring in this case, observed exsolution leading to the occurrence of two 
different Curie temperatures with the mixture of titanomagnetites, and to the enhancement of the higher of these. The exsolution of titanomagnetites began to appear already in the tenth hour of heating at about $300^{\circ} \mathrm{C}$.

In order to find out, if the mixing of titanomagnetites is possible, and how the latter is dependent on the heating of the mineral at a given temperature, three groups of samples were heated up to $800^{\circ} \mathrm{C}$. The samples of the first group were then cooled abruptly (in 6 secs.), the samples of the second group were cooled at speed of $200^{\circ} \mathrm{C}$ per hour after three hours at $800^{\circ} \mathrm{C}$, and the samples of the third group were kept at $800^{\circ} \mathrm{C}$ for 24 hours and then cooled at a speed $200^{\circ} \mathrm{C}$ per hour. The changes in the temperature relation $\sigma_{s}(T)$, which occurred owing to the above mentioned treatment, are shown in Fig. 1 by curves 3- 5 . As can be clearly seen in this case the value of $\sigma_{s o}$ decreases together with the value of the Curie temperature, even in relation to the interval of heating. The temperature of $800^{\circ} \mathrm{C}$ is, therefore, sufficient for the mixing of titanomagnetites to occur even in intervals up to 24 hours. The appropriate values of the specific saturation magnetization and Curie temperatures after this thermal treatment, are given in Table 1.

During heating and thermal treatment, the mineral experiences irreversible changes, which result in the changes of magnetic properties. The change in the character of the temperature dependence of specific saturation magnetization for differently treated samples, can be seen in Fig. 3 a-e. As a result of thermal treatment, the $\sigma_{s}(T)$ curve shows a distinct "flattening" from a roughly parabolic trend to a nearly linear trend. Similar linear relations of specific saturation magnetization and temperature were also observed by Akimoto (1955) and by Bewersdorff (1961), who interpret them as solid solution curves for titanomagnetites

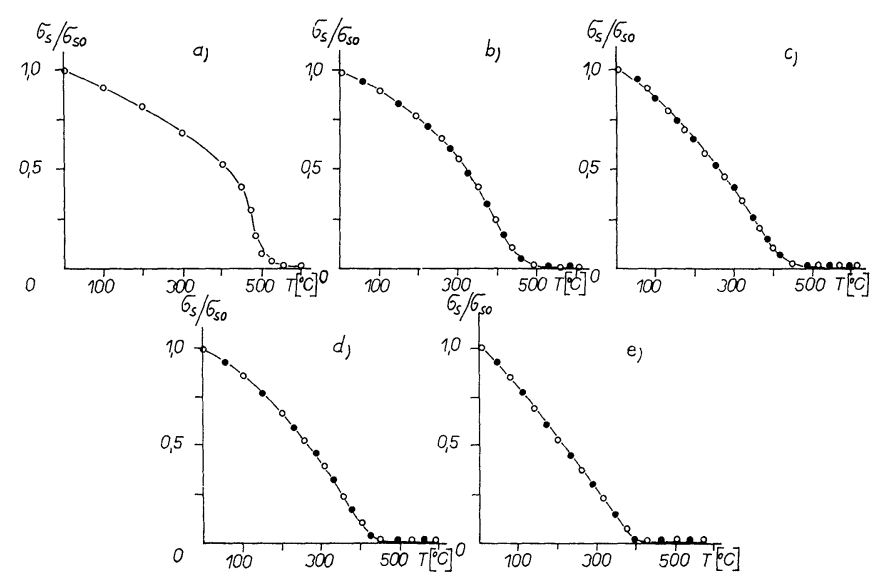

Fig. 3 Change in character of the temperature dependence of the specific saturation magnetization $\sigma_{s}(T) / \sigma_{s o}$; a-natural state, $\mathrm{b}$-after heating up to $600^{\circ} \mathrm{C}$ and cooling, $\mathrm{c}$-after heating up to $800^{\circ} \mathrm{C}$ and abrupt cooling, $\mathrm{d}$-after heating for 3 hours at $800^{\circ} \mathrm{C}$ and cooling by speed $200^{\circ} \mathrm{C}$ per hour, e-after heating for 24 hours at $800^{\circ} \mathrm{C}$ and cooling by speed $200^{\circ} \mathrm{C}$ per hour.

…. points during during heating

.......points during cooling 
with a different $x$-factor, i.e. with different values of saturation magnetization and Curie temperatures.

\section{The Changes in the Properties of Specific Remanent Magnetization}

As was shown in the first part of this paper, the values of $\sigma_{s o}$ and $\theta$ are considerably affected by thermal treatment. This applies to the character of the relation $\sigma_{s}(T)$, as well. As the properties of remanent magnetization are of greater interest to palaeomagnetism, it is important to investgate the changes of the properties of remanent magnetization during thermal treatment. In order to facilitate comparison, the samples were subject to identical thermal treatment.

The value of the specific remanent saturation magnetization at $20^{\circ} \mathrm{C}$ and in the initial state of the mineral was $\sigma_{s r o}=1,74 \mathrm{emu}$ per gr. and the value of the natural remanent magnetization was $\sigma_{n r}=0,596 \mathrm{emu}$ per gr. By comparing the value of the specific saturation magnetization with the value of the specific remanent saturation magnetization, it can readily be seen that the mineral will be magnetically soft, and will display a small coercive force, the values of the critical field $H_{0}$ in which the remagnetization of grains or irreversible shifts of domain walls take place, and which characterise the level of potential barriers in the magnetic material. The basic curve of the relation between the specific remanent magnetization and the magnetic field, if initiated in the demagnetized state, $\sigma_{r}=g(H)$, is

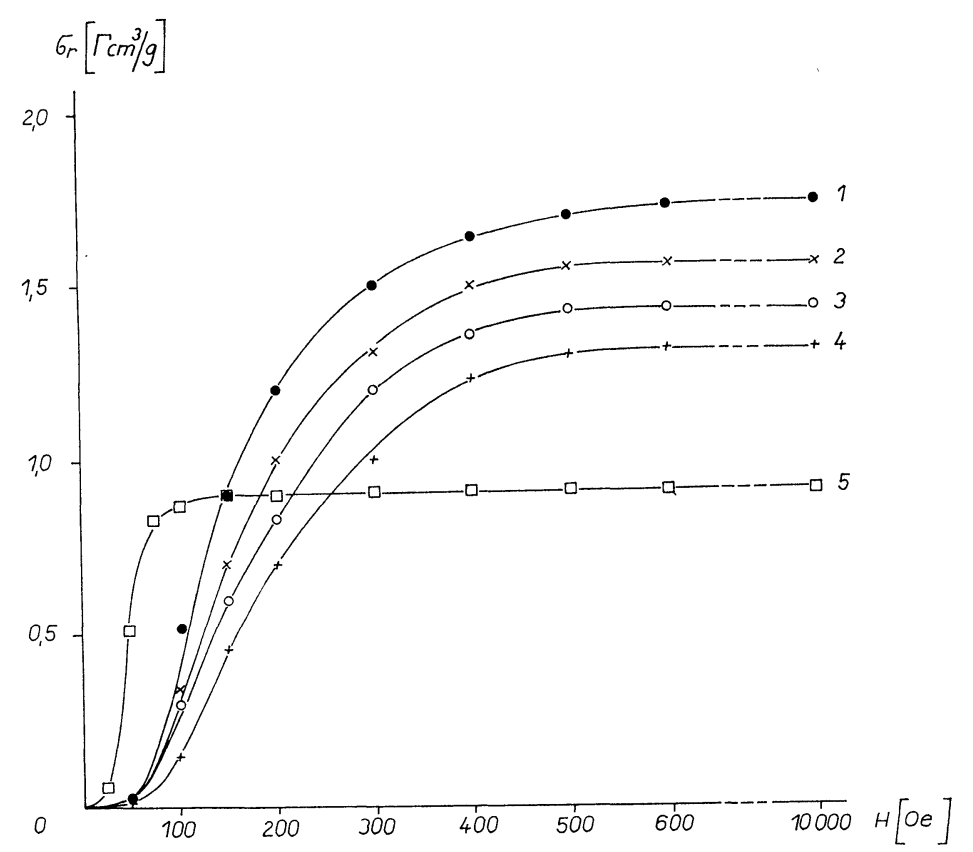

Fig. 4 Change in the relation $\sigma_{r}=g(H)$ during various thermal treatments, the period at a given temperature identical in all cases; curve 1 -natural state, curve 2 after heating up to $400^{\circ} \mathrm{C}$ and cooling by speed $200^{\circ} \mathrm{C}$ per hour, curve 3 after heating up to $500^{\circ} \mathrm{C}$ and cooling, curve 4 -after heating up to $600^{\circ} \mathrm{C}$ and cooling, curve 5 -after heating up to $1200^{\circ} \mathrm{C}$ and cooling. 
numbered 1 in Fig. 4. The effect of thermal treatment also in this case results in a gradual decrease of the specific remanent saturation magnetization, from the value $\sigma_{s r o}=1,74 \mathrm{emu}$ per gr. to $\sigma_{\text {sro }}=1,36$ emu per gr. for a mineral sample heated to $600^{\circ} \mathrm{C}$ (curves 1-4). In contrast to the decrease in saturation magnetization, this decrease is considerably smaller under identical thermal treatment. The comparison of corresponding values can be made with the help of the Table 1. The explanation of this phenomenon from a qualitative aspects for temperatures up to $600^{\circ} \mathrm{C}$, when no further mixing in dependence on the time of heating occurs, can be presented as follows; providing an interpretation of phenomena observed at higher temperatures is not required: The remanent magnetization, according to Vonosovskij and $\mathrm{S} u r(1948)$, is given by the relation

$$
\begin{array}{ll}
\sigma_{r}=\frac{1}{2} \sigma_{s}\left[1-\frac{H_{0}^{2}}{H^{2}}\right] & \text { for } \quad H>H_{0} \\
\sigma_{r}=0 & \text { for } 0 \leq H \leq H_{0}
\end{array}
$$

under the assumptions that the external magnetic field causes shifts of the $180^{\circ}$ domain walls only, that in a demagnetized state the direction of spontaneous magnetization of the domains are completely random, that the direction of the magnetic field is the same everywhere within the sample, and that the values of the critical field $H_{0}$ are identical within the entire volume of the sample. These assumptions, apart from the last one, are usually fulfilled with most materials. Only in the case of strong magnetic fields, deviations from the first assumption are observed; this is caused by the rotation of the vectors of spontaneous magnetization into the direction of the acting field. The last assumption, $H_{0}=$ const., can be substituted, as has been shown in reference (Kočegura, 1965), by a frequency function of the spectral distribution of critical fields, $f\left(H_{0}\right)$, in the mineral. In this case it is possible to express the specific remanent magnetization by the following relation:

$$
\sigma_{r}=\frac{1}{2} \sigma_{s} \int_{0}^{H} f\left(H_{0}\right)\left[1-\frac{H_{0}^{2}}{H^{2}}\right] d H_{0} .
$$

It follows that the changes in the values of the specific remanent magnetization are not only proportional to the values of the specific saturation magnetization, but also to the values of critical fields and their spectral distribu-

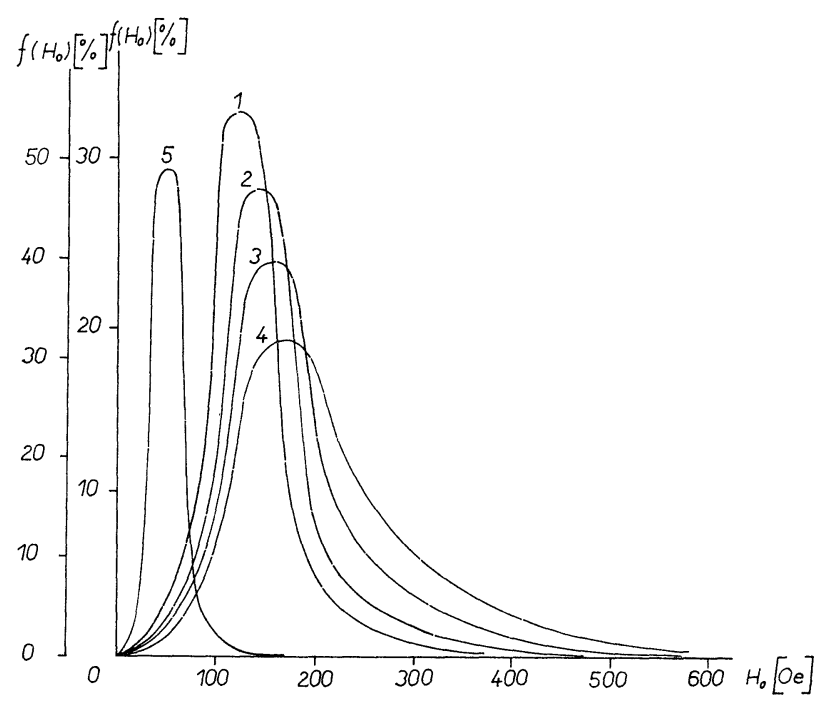

Fig. 5 Change in the function of the frequency distribution of critical fields $H_{o}$ under various thermal treatments ; curve 1 -natural state, curve 2 -after heating up to $400^{\circ} \mathrm{C}$ and cooling, curve 3 -after heating up to $500^{\circ} \mathrm{C}$ and cooling, curve 4 after heating up to $600^{\circ} \mathrm{C}$ and cooling, curve 5 -after heating up to $1200^{\circ} \mathrm{C}$ and cooling. 
tion. In order to explain the smaller decrease of the remanent saturation magnetization, it is necessary for the values of the critical fields to be enhanced, i.e. the curve of the spectral distribution of the critical fields has to be shifted towards higher field values. The curves of the spectral distribution of critical fields can be derived by two independent ways, which give practically identical values for a given mineral (Kropáček, 1966; Kočegura, 1965). Derived frequency curves of the spectral distribution of critical fields $f\left(H_{0}\right)$, for samples under different thermal treatment, are given in Fig. 5, (curves 1-4). The above considerations are clearly sup-

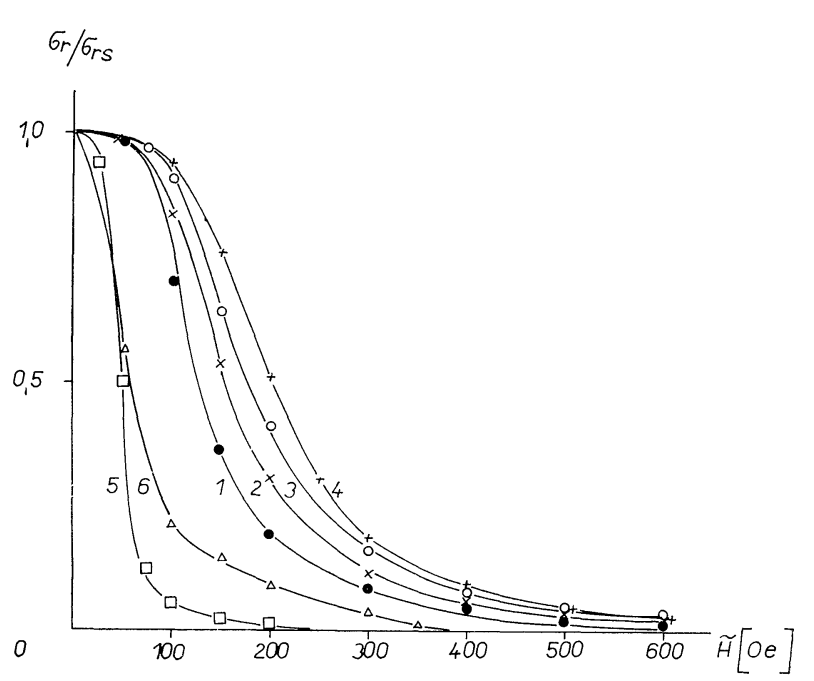

Fig. 6 Curves of A.C. demagnetization of remanent saturation magnetization under various thermal treatments ; curve 1 -natural state, curve 2-after heating up to $400^{\circ} \mathrm{C}$ and cooling, curve 3-after heating up to $500^{\circ} \mathrm{C}$ and cooling, curve 4 -after heating up to $600^{\circ} \mathrm{C}$ and cooling, curve 5-after heating up to $1200^{\circ} \mathrm{C}$ and cooling, curve 6-A.C. demagnetization of natural remanent magnetization. ( $H$ in P.V.) ported by the graph, and a shift of the curve maxima towards higher field values can be seen. The material has become magnetically harder due to thermal treatment, in other words the levels of the potential barriers have been enhanced. These conclusions are also supported by the curves of A.C. demagnetization of the specific remanent saturation magnetization shown in Fig. 6, which display the conservation of remanent magnetization at higher A.C. demagnetization field values. A further interesting point can be deduced from the curves in Fig. 5. The frequency curves $f\left(H_{0}\right)$, retain, even after thermal treatment, the shape of a normal gaussian distribution, although the maximum and the dispersion are changed.

Thermomagnetic analysis of the mineral, carried out by measuring the temperature dependence of the specific remanent magnetization of saturation, is described in Fig. 7 (curve 1), and shows that, together with the values of the remanent saturation magnetization, the values of Curie temperatures changes as well. These curves display a "flattening" in the same way as those in Fig. 3, although it is not nearly so distinct. A comparison of Fig. 1 and Fig. 7 shows that there is no considerable difference between a thermomagnetic analysis carried out by considering the temperature dependence of saturation magnetization, and a thermomagnetic analysis carried out by considering remanent saturation magnetization.

Long-termed thermal treatment by heating up to $600^{\circ} \mathrm{C}$, in the same way as in the first part of this paper, did not alter the appropriate magnetic characteristics. Also, the order conclusions made on the basis of the properties of the remanent magnetization, support the 
conclusion in the first part of paper, which were made on the basis of the basis of the properties of specific saturation magnetization. According to what was said about the decrease of remanent magnetization accompanied by the increase in the values of the critical fields, one could assume that by heating the mineral up to $800^{\circ} \mathrm{C}$ a further increase of critical field values within, should ensue. This increase, though, was only observed with the sample which was cooled abruptly from $800^{\circ} \mathrm{C}$, whereas the sample which had been heated for longer periods, and cooled slowly, displayed decreases in remanent magnetization values as well as in critical field values. These changes cannot be explained by the above mentioned mechanism, but a further variable, time, has to be introduced, which

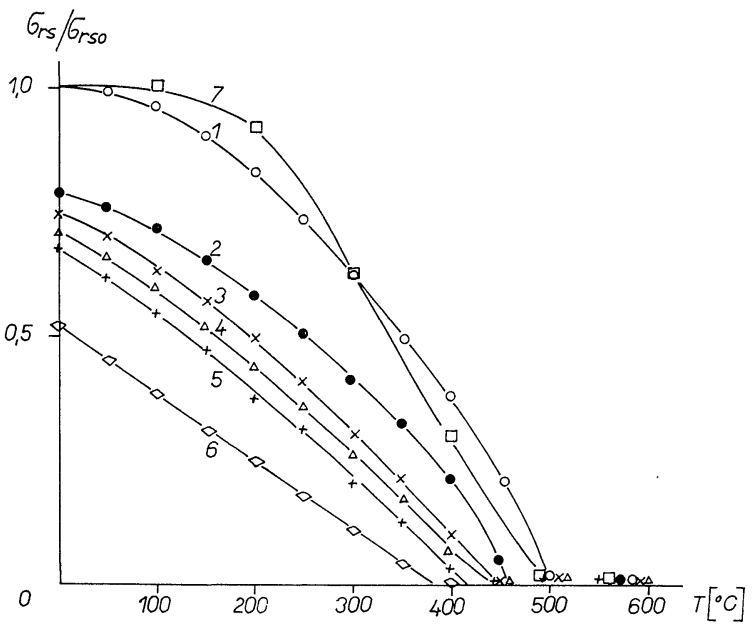

Fig. 7 Temperature dependence of specific remanent saturation magnetization $\sigma_{r s}(T) / \sigma_{r s o}$ under various thermal treatments; curve 1 -natural state, curve 2 -after heating up to $600^{\circ} \mathrm{C}$ and cooling, curve 3 -after heating up to $800^{\circ} \mathrm{C}$ and abrupt cooling, curve 4-after heating up to $800^{\circ} \mathrm{C} 3$ hours and cooling by speed $200^{\circ} \mathrm{C}$ per hour, curve 5 -after heating up to $800^{\circ} \mathrm{C} 24$ hours and cooling by speed $200^{\circ} \mathrm{C}$ per hour, curve 6 after heating up to $1200^{\circ} \mathrm{C}$ and cooling by speed $200^{\circ} \mathrm{C}$ per hour, curve 7 -temperature dependence of natural remanent magnetization.

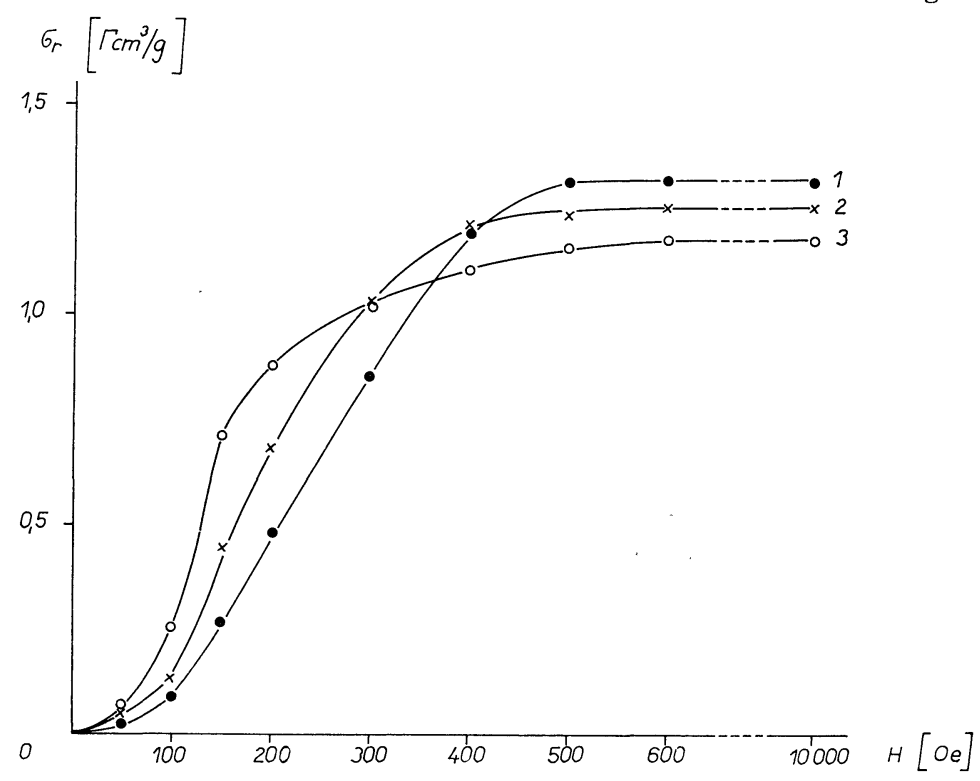

Fig. 8 Change in the dependence specific remanent magnetization $\sigma_{r}=g(H)$ under various thermal treatments at temperature $800^{\circ} \mathrm{C}$; curve 1 -after abrupt cooling, curve, 2-after 3 hours at $800^{\circ} \mathrm{C}$ and cooling by speed $200^{\circ} \mathrm{C}$ per hour, curve 3 -after 24 hours at $800^{\circ} \mathrm{C}$ and cooling by speed $200^{\circ} \mathrm{C}$ per hour. 
effects the course and degree of mixing, irrelevant at temperatures up to $600^{\circ} \mathrm{C}$. As has been experimentally proved in a number of papers (Kneller 1962), the influence of long-termed heating results in the homogeneization of the mineral, which leads to the decrease in the levels of the potential barriers. This also been partly proved by a control heating treatment up to $1200^{\circ} \mathrm{C}$ over a period of 1 hour and subsequent slow cooling. The relations for the mineral, treated in this way, are given in Figs. 4 to 6 by curves 5 , and in Fig. 7 by curve 6 . The latter clearly show that heating up to $1200^{\circ} \mathrm{C}$ already leads ta a consideraable change in magnetic characteristics, the saturation state for remanent magnetization is reached under very weak fields, demagnetization is very quick, and the Curie temperature decreases. Critical field values in this case have a very narrow spectrum, which proves the homogeneity of the sample. Clearly a thorough mixing of the titanomagnetites has already occured, and nearly all potential barriers have been removed. The curves describing the properties of remanent magnetization under various thermal treatment up to tempera tures of $800^{\circ} \mathrm{C}$ are given in Fig. 7 to 10 .

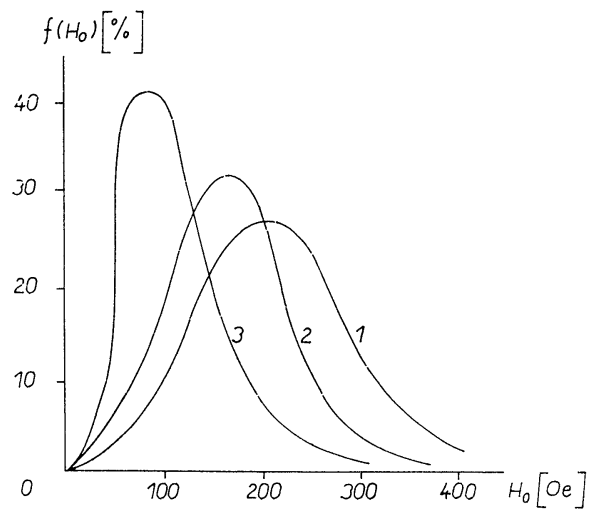

Fig. 9 Change in the function of the frequency distribution of critical fields $H_{o}$ due to different thermal treatments at temperature $800^{\circ} \mathrm{C}$; curve 1 -after abrupt cooling, curve 2 -after 3 hours at $800^{\circ} \mathrm{C}$ and cooling by speed $200^{\circ} \mathrm{C}$ per hour, curve 3 after heating 24 hours at $800^{\circ} \mathrm{C}$ and cooling by speed $200^{\circ} \mathrm{C}$ per hour.

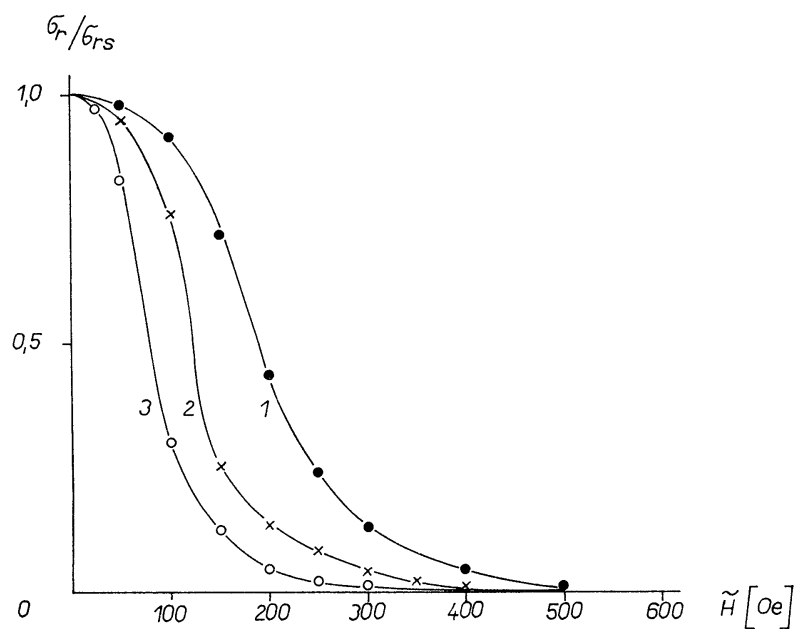

Fig. 10 Curves of A.C. demagnetization of specific remanent saturation magnetization $\sigma_{r s o}$ under varions thermal treatments at temperature $800^{\circ} \mathrm{C}$; curve 1 -after abrupt cooling, curve 2after heating 3 hours at $800^{\circ} \mathrm{C}$ and cooling, curve 3 -after heating 24 hours at $800^{\circ} \mathrm{C}$ and cooling. ( $H$ in P.V.)

\section{The Properties of Natural Remanent Magnetization}

For the sake of comparison, with the properties of remanent saturation magnetization, curves describing the dependence of natural remanent magnetization on the demagnetization effects of temperature and of an A.C. demagnetizing field, are shown in Figs. 6, (curve 
6 ) and 7 (curve 7). The value of the natural remanent magnetization is $\sigma_{n r}=0,596 \mathrm{emu}$ per gr. and constitutes roughly a third of the remanent saturation magnetization in the natural state of the mineral. Its demagnetization in an A.C, field is very quick, and the magnetization is very unstable. The value of the thermoremanent magnetization acquired by cooling from $600^{\circ} \mathrm{C}$ in the Earth's magnetic field, is $\sigma_{r t}=7,2 \cdot 10^{-2}$ emu per gr., which is considerably lower than the value of the natural remanent magnetization. It is clear that this low value was not caused by the anomalous value of the geomagnetic field in the geological period of of the origin of the mineral, but that it was caused by changes accruing in the mineral under the influence of heating up to $600^{\circ} \mathrm{C}$, described from a magnetic point of view in the above.

\section{Conclusions}

An interesting property of a spinel structure mineral with anomalous magnetization has been found. It can be described as a kind of "thermal memory of the thermoremanent magnetization", ensuing from Fig. 2, and enabling the temperature to which the mineral was heated afted its origin to be determined from values of the saturation magnetization and the value of the Curie temperature, providing the temperatures fulfill $350^{\circ} \mathrm{C}<T \leq 600^{\circ} \mathrm{C}$. This property could be of certain, although special, use in rock-magnetism.

Different magnetic characteristic corresponding to thermal treatment up to $600^{\circ} \mathrm{C}$ and over $600^{\circ} \mathrm{C}$ were determined. Up to this temperature magnetic characteristics do not change with the time of heating (providing it is smaller than 24 hours). Whereas above these temperatures a distinct influence of the heating time on magnetic characteristics could be seen.

A qualitative attempt was made at elucidating the difference in the decrease of remanent and saturation magnetization under identical thermal treatment, which is not unambiguous, and which calls for further investigation.

It was shown that these changes in the mineral influence the course of changes in the properties of the natural remanent magnetization, and that it would be suitable to take interest in these changes with other minerals in order to facilitate more accurate thermal cleaning used in palaeomagnetisam.

\section{References}

Akimoto S.: Magnetic Properties of Ferromagnetic Minerals Contained in Igneous Rocks. Japan. Jour. Geophys. 2, 1, 1955.

Akimoto S., Katsura T., Yoshida M.: Magnetic Properties of $\mathrm{TiFe}_{2} \mathrm{O}_{4}-\mathrm{Fe}_{3} \mathrm{O}_{4}$ System and Their Change with Oxidation. Jour. Geomag. Geoel. 9, 165, 1957.

Bewersdorff A.: Der Einfluss der Entmischung auf die remanente Magnetisierung von Titanomagnetiten. Zeitschr. f. Geophys. 27, 215, 1961.

Frölich F.: Ein Gerät zur Bestimmung der Zusammensetzung sowie der thermischen Zustandsänderungen von magnetischen Gesteinen und Werkstoffen, Jahrbuch 1958 des Adolf-Schmidt-Observatorium für Erdmagnetisms in Niemegk 129, 1960.

Kneller E.: Ferromagnetismus, Springer Verlag Berlin 1962.

Kobayashi K.: Chemical Remanent Magnetization of Ferromagnetic Minerals and Its Application to 
Rock Magnetism. Jour. Geomag. Geoel. 10, 99, 1959.

Kočegura V.V.: Ob analize krivoj normalnoj ostatočnoj namagničennosti. Sbornik: Nastojaščee i prošloe magnitnogo pola Zemli. Izd. Nauka Moskva 154, 1965.

Kropáček V.: Some Properties of the Natural Remanent Magnetization and Thermoremanent Magnetization of Rocks. Travaux Geophysique 13, 441, 1966.

Nagata T. Rock Magnetism, Maruzen, Tokyo, 1961.

Stiller H., Volstädt H.: Bestimmung ferri und antiferromagnetischcr Curie-Temperaturen mittels Differentialthermoanalyse, Zeitsch. f. Geophys. 31, 212, 1965.

Vonsovskij S.V., Šur J.S.: Ferromagnetizm. Gostechizdat Moskva, 1948. 